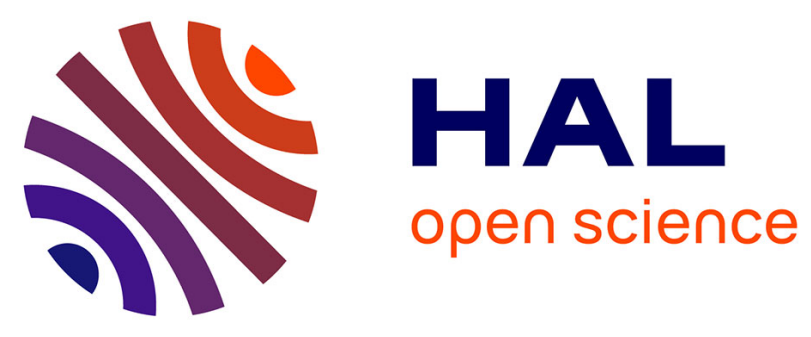

\title{
Variation in management of early breast cancer in the Netherlands, 2003-2006
}

\author{
L.N van Steenbergen, L.V. van de Poll-Franse, M.W.J.M. Wouters, Mlea \\ Jansen-Landheer, J.W.W. Coebergh, H Struikmans, V.C.G. Tjan-Heijnen, \\ C.J.H. van de Velde
}

\section{To cite this version:}

L.N van Steenbergen, L.V. van de Poll-Franse, M.W.J.M. Wouters, Mlea Jansen-Landheer, J.W.W. Coebergh, et al.. Variation in management of early breast cancer in the Netherlands, 2003-2006. EJSO - European Journal of Surgical Oncology, 2010, 36, 10.1016/j.ejso.2010.06.021 . hal-00612393

\section{HAL Id: hal-00612393 https://hal.science/hal-00612393}

Submitted on 29 Jul 2011

HAL is a multi-disciplinary open access archive for the deposit and dissemination of scientific research documents, whether they are published or not. The documents may come from teaching and research institutions in France or abroad, or from public or private research centers.
L'archive ouverte pluridisciplinaire HAL, est destinée au dépôt et à la diffusion de documents scientifiques de niveau recherche, publiés ou non, émanant des établissements d'enseignement et de recherche français ou étrangers, des laboratoires publics ou privés. 


\section{Accepted Manuscript}

Title: Variation in management of early breast cancer in the Netherlands, 2003-2006

Authors: L.N van Steenbergen, L.V. van de Poll-Franse, M.W.J.M. Wouters, Mlea Jansen-Landheer, J.W.W. Coebergh, H Struikmans, V.C.G. Tjan-Heijnen, C.J.H. van de Velde

PII:

S0748-7983(10)00197-6

DOI:

10.1016/j.ejso.2010.06.021

Reference: YEJSO 3009

To appear in: European Journal of Surgical Oncology

Received Date: 4 May 2010

Accepted Date: 8 June 2010

Please cite this article as: van Steenbergen LN, van de Poll-Franse LV, Wouters MWJM, JansenLandheer M, Coebergh JWW, Struikmans H, Tjan-Heijnen VCG, van de Velde CJH. Variation in management of early breast cancer in the Netherlands, 2003-2006, European Journal of Surgical Oncology (2010), doi: 10.1016/j.ejso.2010.06.021

This is a PDF file of an unedited manuscript that has been accepted for publication. As a service to our customers we are providing this early version of the manuscript. The manuscript will undergo copyediting, typesetting, and review of the resulting proof before it is published in its final form. Please note that during the production process errors may be discovered which could affect the content, and all legal disclaimers that apply to the journal pertain. 


\section{Variation in management of early breast cancer in the Netherlands, 2003-2006}

LN van Steenbergen', LV van de Poll-Franse 1,2 *, MWJM Wouters ${ }^{3}$, MLEA Jansen-Landheer ${ }^{4}$, JWW Coebergh'1,5, H Struikmans ${ }^{6,7}$, VCG Tjan-Heijnen ${ }^{8}$, CJH van de Velde ${ }^{9}$

' Comprehensive Cancer Centre South, Eindhoven, The Netherlands

${ }^{2}$ Center of Research on Psychology in Somatic diseases (CORPS), Tilburg University, Tilburg, The Netherlands

3 Dept. of Surgery, Netherlands Cancer Institute, Antoni van Leeuwenhoek Hospital, Amsterdam, The Netherlands

${ }^{4}$ Comprehensive Cancer Centre Amsterdam, Amsterdam, The Netherlands

5 Dept. of Public Health, Erasmus University Medical Centre, Rotterdam, The Netherlands ${ }^{6}$ Dept. of Radiotherapy, Leiden University Medical Centre, Leiden, The Netherlands

7 Dept. of Radiotherapy, Medical Centre Haaglanden, The Hague, The Netherlands

8 Division of Medical Oncology, Dept. of Internal Medicine, GROW - School for Oncology and Developmental Biology, Maastricht University Medical Center, Maastricht

9 Dept. of Surgery, Leiden University Medical Centre, Leiden, The Netherlands

* Corresponding author

Address for correspondence:

Comprehensive Cancer Centre South, PO Box 231, 5600 AE Eindhoven, the Netherlands Tel: +31-40-2971616 fax: $+31-40-2971610$

Email: research@ikz.nl

Running head: Variation in treatment of early breast cancer in the Netherlands, 2003-2006

Key words: early breast cancer, breast conserving surgery, axillary lymph node dissection, sentinel lymph node procedure, adjuvant systemic therapy

This study was performed for the working party 'Quality of cancer care' of the Signalling Committee Cancer of the Dutch Cancer Society 


\section{Abstract}

Background: To describe variation in staging and primary treatment by hospital characteristics including type and volume and region in patients with early breast cancer (BC) in the Netherlands, 2003-2006 after completion of national guidelines in 2002.

Methods: All patients newly diagnosed with invasive BC in 2003-2006 and recorded in the Netherlands Cancer Registry were included ( $n=51354$ ). Multivariable logistic regression analyses examined the influence of patient and hospital characteristics, also by region, on type of breast surgery, axillary lymph node dissection (ALND), sentinel node procedure (SNP), and adjuvant irradiation and/or systemic treatment.

Results: Patients $<40$ years more often underwent breast conserving surgery (BCS) in general hospitals (OR 1.4 (95\% Cl 1.1-1.5)) than in teaching and academic hospitals, whereas patients of 40-69 years less often received BCS in an academic hospital (OR 0.9 (95\% Cl 0.8-1.0)) than in teaching hospitals. Patients with PTl-2NO cancer more often underwent primary ALND in a general hospital than in a larger teaching or academic hospital. Type of hospital did not seem to affect utilization of adjuvant systemic therapy, but patient age and tumour size and grade did. Over time, patients more often received SNP, BCS, and adjuvant systemic therapy, primary ALND being on the decline, but with substantial regional variation between geographic regions.

Conclusion: With detailed evidence-based national guidelines since 2002 the considerable regional and hospital variation in staging procedures and primary treatment among newly diagnosed patients with early breast cancer in the Netherlands decreased markedly, suggesting the presence of late adaptors rather than specific hospital characteristics. 


\section{Introduction}

Breast cancer is the most frequent cancer in females in the Netherlands, with a lifetime risk of 12-13\%1. Early detection, mainly due to population-based screening, and adjuvant treatment resulted in an improved survival of patients with breast cancer and lower mortality since the mid 1990s. Breast cancer staging and treatment is evolving and, therefore, clinical practice guidelines were developed since 1999, coming into practice in $2002^{2}$.

Oncological care for breast cancer is rapidly changing through surgical, pharmacological and technological innovations, thereby also becoming increasingly subspecialized. Quality increasingly becomes measurable, being considered as vital for both patients and doctors and, last but not least for health insurance companies. Important aspects are thought to be volume ${ }^{3-8}$ and type of hospital9, 10, depending on the type of cancer, population density, and prosperity of region or country.

According to the Dutch clinical practice guidelines of 2002, patients with early stage (TIT2MO) breast cancer are generally eligible for breast conserving surgery (BCS), unless they are of young age or prefer otherwise. Patients who undergo BCS should receive adjuvant radiotherapy at any age ${ }^{2}$. The sentinel lymph node procedure (SNP) is advised in patients with a clinically node-negative breast tumour, while a primary axillary lymph node dissection (ALND) is advised in all other patients. ${ }^{2}$ Adjuvant chemotherapy, HER2-targeted therapy and hormone therapy have proven to be effective in preventing or delaying relapses and increasing survival in patients with early stage or locally advanced breast cancer. ${ }^{11,} 12$ Therefore, patients with a node-positive tumour or a node-negative tumour with unfavourable characteristics should receive adjuvant systemic treatment. ${ }^{2}$ In the Netherlands a biannual mammography mass screening program for breast cancer in women from 50 to 70 years was gradually introduced since 1990, being fully implemented since 1997 and extended to women of 75 years since 1999.

The purpose of this nationwide study was to describe variation in staging and treatment of patients with early breast cancer by hospital characteristics including type and volume and by region. The results of this study on all patients newly diagnosed in the Netherlands in 20032006 will support the ongoing efforts to improve quality of care for breast cancer patients in the Netherlands and abroad. 


\section{Methods}

\section{Data collection}

We used the population-based database from the Netherlands Cancer Registry (NCR), which started in 1989 and is maintained and hosted by the Comprehensive Cancer Centres (CCCS).' The NCR is based on notification of all newly diagnosed malignancies in the Netherlands by the national automated pathological archive (PALGA) that covers 70 laboratories. Additional sources are the national registry of hospital discharge data, which accounts for up to $8 \%$ of new cases, ${ }^{13}$ and regional radiotherapy institutes. Information on patient characteristics like date of birth, and tumour characteristics such as date of diagnosis, histology, stage (Tumour Lymph Node Metastasis (TNM) classification), ${ }^{14}$ grade, and primary treatment as well as staging procedures, are obtained routinely by data registration clerks from the cancer registry from the medical records about nine months after diagnosis. ${ }^{13}$ The quality of the data is high due to thorough training of the data managers and a variety of computerized consistency checks at regional and national level. Completeness is generally estimated to be at least $95 \%$ for all tumours but higher for breast cancer due to its high level of histological verification. ${ }^{15}$ For the current analysis, hospital characteristics including type and volume were retrieved from Prismant, an organisation which collects objective data about hospitals for e.g. quality of care assessment. ${ }^{16}$ Presence of the 21 institutes of radiotherapy was known through the Comprehensive Cancer Centres.

\section{Patients}

For the present study, all female cases with primary invasive primary breast cancer (ICD-0: C50.0) newly diagnosed in the period 2003-2006 in the Netherlands were included ( $n=51354$ ). Exclusion criteria were diagnosis by autopsy, living and treatment abroad, incomplete registration status in the NCR, clinical diagnosis only, histology of sarcoma, lymphoma, Paget's disease, neuro-endocrine tumour or carcinoid. Reported stage is postoperative, and clinical when postoperative stage was unknown. Patients who received BCS followed by mastectomy without signs of relapse were coded as having had mastectomy.

Hospitals

The categorization of hospitals was based on data from Prismant for the period 2003-2005. Hospitals with several locations, but organized as one hospital in 2003 were considered as one hospital. Patients were considered to be treated in the hospital where the tumour was diagnosed. A non-teaching hospital was categorized as a general hospital. A teaching hospital provides in-house training to surgical and/or internal medicine residents. An academic hospital was a teaching hospital uniquely affiliated with a university. The one specialized oncology centre in the Netherlands was classified as an academic hospital. Hospital volume was based on the mean number of breast cancer diagnoses per year in the 
study period, and was categorized into $<150$ and $\geq 150$ diagnoses per year. Hospital type was categorized based on teaching hospital for surgery and hospital volume, resulting in six categories. The regions were based on the areas served by one of the nine CCCs. Each CCC serves the population in an area of five to twenty hospitals. Each of the hospitals was affiliated to one CCC only.

Data were analysed by researchers of the nine CCCs in the Netherlands, supervised by experienced clinicians. The CCCs intend to improve and monitor the quality of cancer care by provision of consultancy services, implementation of national guidelines, improving organisation of cancer care, coordinating palliative care, and organising the cancer registry.

\section{Statistical analyses}

Patient, tumour, and hospital of staging and treatment characteristics as well as region were described in relation to received treatment. Surgical and radiotherapy treatment were analysed according to stage. Multivariable logistic regression analysis was performed stratified by age ( $<40$ years, $40-69$ years, and $\geq 70$ years) to examine the influence of hospital type and volume on the possibility to receive BCS with adjustments for the presence of radiotherapy in a hospital, region, and year of diagnosis. Since there was significant interaction between type and volume of a hospital, these variables were merged into one variable of both type and volume of a hospital. Similarly, multivariable logistic regression analysis was performed to examine determinants of ALND, which was also done for the application of adjuvant systemic treatment. In this analysis the independent effect of hospital type and volume were analysed separately, since no interaction was found between these factors in relation to adjuvant systemic therapy and then stratified by age $1<55$ and $\geq 55$ years). Variation in utilization of ALND and adjuvant systemic treatment was displayed as scatter plots with the average number of breast cancer patients per hospital on the X-axis and of ALNDs or adjuvant systemic treatment on the Y-axis. Hospital type was classified through symbols in the scatter plot. All analyses were done in SAS (version 9.1, SAS Institute, Cary, NC). $95 \%$ Confidence intervals were estimated and a p-value of 0.05 was considered statistically significant. 


\section{Results}

In 2003, 12460 women were diagnosed with primary invasive breast cancer in the Netherlands, which gradually increased to 13280 in 2006, an increase of $7 \%$ in four years. Over $40 \%$ of patients were treated in a large teaching hospital, $33 \%$ in a small general hospital, and only $8 \%$ in an academic hospital (Table 1). No change in stage distribution was seen over time in the period 2003-2006 (data not shown).

\section{Surgery}

Most patients underwent BCS with radiotherapy, although this depended on the stage of disease, being $63 \%$ of patients with stage I disease, $41 \%$ in stage II, and $19 \%$ in stage III. Almost all patients who underwent BCS received radiotherapy. Mastectomy was the treatment of choice in $51 \%$ of patients with stage II disease and in $69 \%$ with stage III (Figure 1). Application of BCS in patients with $\mathrm{T} 1 \mathrm{~T} 2 \mathrm{NO}$ disease varied from $30 \%$ to $82 \%$ among hospitals (data not shown). Patients aged $<40$ years were more likely to receive BCS in a general (nonteaching) hospital, whereas patients of $\geq 70$ years less often received BCS in a small general or teaching hospital. Patients aged 40-69 years less often received BCS in a small hospital (Table 2a). After adjustments similar results were found, although patients aged 40-69 years were less likely to receive BCS in academic centres. The presence of radiotherapy in an - often larger hospital positively affected the chance for BCS in patients 40-69 years. Over time, more patients underwent BCS compared to mastectomy, especially in older women, but with substantial variation between geographic regions in the Netherlands (Table 2b). When considering type of hospital alone, patients $<40$ years were more likely to receive BCS (OR 1.3 (95\% Cl 1.1-1.5)), contrasting patients $\geq 70$ years (OR 0.9 (95\% Cl 0.8-0.9)) when treated in a general hospital compared with a teaching hospital. Academic hospitals were not different from teaching hospitals with regard to choice of BCS for patients aged $<40$ years or $\geq 70$ years. However, patients of 40-69 years treated in academic hospitals were less likely to receive BCS (OR 0.9 (95\% Cl 0.8-1.0)) compared with teaching hospitals.

Axillary lymph node dissection

After a start at larger scale in 1998, the sentinel lymph node procedure (SNP) was applied in 2003 in $59 \%$ of T1T2 NO breast cancer patients, which became $78 \%$ in 2006 . Consequently, primary ALND decreased over time from 22\% in 2003 to $11 \%$ in 2006 . Patients with T1T2 NO disease more often received primary ALND in a general hospital, followed by the teaching and the academic hospitals. Older age ( $\geq 70$ years) and clinical $T 2$ stage were positively associated with application of ALND, clearly decreasing over time. There still was large but declining variation in ALND among regions (Table 3). T1 T2 NO patients treated in a general hospital were more likely to receive ALND (OR 1.4 (95\% Cl 1.3-1.5)), but less in an academic hospital (OR 0.9 (95\% Cl 0.8-1.0)), compared to a teaching hospital. ALND in NO patients 
varied from $5 \%$ to $70 \%$ between hospitals, the proportions being higher in a general or low volume hospital than in a teaching or academic hospital (Figure 2).

Adjuvant systemic treatment

Multivariable logistic regression analyses showed that hospital factors including type and volume as well as the presence of radiotherapy in a hospital did not affect the odds of receiving adjuvant systemic therapy in T1T2 NO patients. This decreased sharply with the rise of age, but was higher for patients with a T2 tumour or a poor differentiation grade, and also over time (Table 4). Application of adjuvant systemic treatment in T1T2 NO breast cancer patients ranged from $20 \%$ to $45 \%$ between hospitals, being larger in low volume hospitals (Figure 3). 


\section{Discussion}

In this nationwide study we have shown that breast cancer, as a very common tumour with generally accepted treatment guidelines since 2002, still exhibited considerable variation in staging and treatment across the Netherlands in the various hospitals, regardless of hospital size. Significantly more patients $<40$ years underwent BCS in general hospitals compared to teaching and academic hospitals, whereas women aged 40-69 years less often received BCS in an academic hospital versus teaching hospitals. Moreover, too many patients with clinically node-negative T1T2 disease diagnosed in general hospitals still received primary ALND, in the absence of a SNP compared to teaching and academic hospitals. However, almost all patients undergoing BCS received radiotherapy. The prescription of adjuvant systemic therapy did not depend on hospital type, but there was no specification according to regimen. Differences in surgical breast treatment and lymph node staging were still seen between geographic regions, but decreased over time.

Surgical breast treatment

According to the first national, Dutch clinical practice guidelines of 2002 patients with early stage breast cancer are generally eligible for BCS. There are exceptions besides the size of the fumour in relation to the size of the breast, because higher local recurrence rates have been reported in patients aged $<40$ years compared to those $>60$ years. 17, 18 But the preference of the treating surgeon and the wish of the patient are of major importance. We found that hospital type and volume as well as region were important determinants of BCS in each age group, as also found in a French randomized trial. ${ }^{19}$ In the US, the mastectomy rate has been rising again since 2003, especially in younger patients. ${ }^{20,21}$ This trend is not yet observed in the Netherlands, although patients of 40-69 years received less often BCS in academic centres than in general and teaching hospitals. This might indicate the start of a change towards an increasing mastectomy rate, also in younger women.

Lymph node analysis

Lymph node analysis is of critical importance for adequate staging of patients with early breast cancer. Since the introduction of ALND has been the standard of care for axillary lymph node staging, until long-term complications of this procedure appeared to be relatively common 22, 23 without conferring a gain in life-expectancy. In 1996, the SNP was introduced in a few hospitals in the Netherlands with supposedly similar staging capacities 24 , 25, 26, 27 but with markedly lower morbidity. ${ }^{28}$ Therefore, Dutch guidelines developed between 2000 and 2002, stated that most early stage breast cancer patients should receive SNP, for which often investments in nuclear detection equipment and training were needed. Although rapidly decreasing over time the general hospitals still performed too many ALNDs in the study period. Moreover, during the study period the indication for SNP changed with an 
increase in the cut-off value of tumour size from 3 to $5 \mathrm{~cm}$, but SNP seems contra-indicated due to e.g. multifocality of the tumour or disturbed lymph drainage.

Adjuvant systemic treatment

Adjuvant chemotherapy, hormonal therapy and trastuzumab have increasingly been proven to be effective in preventing or delaying relapses and increasing survival in patients with early stage breast cancer, also at older age.11,12 Therefore, these therapies have become part of the treatment plan for many of these patients. Guidelines for adjuvant systemic treatment have evolved over time and strategies have become more tumour and patient-specific than ever before. ${ }^{2}, 29$ The rising trend in the use of adjuvant systemic treatment of breast cancer patients was described earlier in southern Netherlands and the US. ${ }^{30}, 31$ Our finding that patients with a large or poorly differentiated tumour more often received adjuvant systemic treatment is in line with the literature and guidelines. ${ }^{31}, 32$ Hospital variation in utilization of adjuvant systemic treatment in early stage node negative breast cancer patients was also found in the southern Netherlands during 2003-2006, when the proportion of adjuvant systemic treatment ranged between $26-42 \% .{ }^{31}$

Quality of care

The large, but decreasing variation in breast cancer care for patients with early breast cancer between the various hospitals in both application of ALND and adjuvant systemic treatment cannot only be explained by patient or tumour characteristics, but is likely to result from differential fast and slow adaptors. But to what extent was the delayed introduction of the SNP or adjuvant systemic treatment in hospitals acceptable, since the SNP and adjuvant systemic treatment have proven their effectiveness in international literature since about 2005.11, 12, 26, 27 In medical oncology, the usual consultancy of experts in oncology meetings in the Netherlands should lead to small differences in application of adjuvant systemic treatment between academic, teaching and general hospitals. But, the consultancy structure is less common in surgical-oncological treatment, because surgical experience is generally supposed to be larger in general and teaching hospitals. Therefore, a specific consultancy structure for surgical staging and treatment of breast cancer patients should be considered. The differences in care between the regions probably reflect differences in previous academic or large teaching hospital practices transmitted by training.

The results of the analyses on intermediate outcome in this study must be interpreted carefully, not only because hospital characteristics such as type and volume, may be rough proxies for hospital characteristics like anaesthesia equipment and nurse-patient ratio. Patient factors like comorbidity and socioeconomic status could also partly explain the observed associations with outcome.33, 34 
In conclusion, there was considerable variation in quality of care for patients with early breast cancer in the Netherlands after, albeit limited, adjustment for case mix (only age, tumour size and grade) in the period 2003-2006, just after the first national guideline became official. The differences, especially concerning breast surgery and axillary lymph node staging could be partly explained by hospital characteristics such as presence of specialist training and volume of care, but there also seemed to be differential loco-regional practices. Variation in application of adjuvant systemic treatment seemed to be mainly caused by patient and tumour characteristics. Research of the determinants of the differences should not only focus on case-mix and hospital characteristics, but should also address often selective, referral patterns and thus provide combined regional analysis. There are certainly gains to be attained. The situation in 2010 is likely to be much better, already. 


\section{Acknowledgements}

The authors would like to thank the working group Output of the NCR for providing data from the cancer registry and all the members of the Quality of Cancer Care working party of the Dutch Cancer Society for financing. 


\section{References}

1. www.ikcnet.nl. accessed on 03-04-2010.

2. Www.oncoline.nl. accessed on 18-04-2010.

3. van Lanschot JJ, Hulscher JB, Buskens CJ, Tilanus HW, ten Kate FJ, Obertop H. Hospital volume and hospital mortality for esophagectomy. Cancer 2001;91(8):1574-8.

4. Wouters MW, Wijnhoven BP, Karim-Kos HE, et al. High-volume versus low-volume for esophageal resections for cancer: the essential role of case-mix adjustments based on clinical data. Annals of surgical oncology 2008;15(1):80-7.

5. Begg CB, Cramer LD, Hoskins WJ, Brennan MF. Impact of hospital volume on operative mortality for major cancer surgery. Jama 1998;280(20):1747-51.

6. Finlayson EV, Goodney PP, Birkmeyer JD. Hospital volume and operative mortality in cancer surgery: a national study. Arch Surg 2003;138(7):721-5; discussion 6.

7. Roohan PJ, Bickell NA, Baptiste MS, Therriault GD, Ferrara EP, Siu AL. Hospital volume differences and five-year survival from breast cancer. American journal of public health 1998;88(3):454-7.

8. Bilimoria KY, Bentrem DJ, Feinglass JM, et al. Directing surgical quality improvement initiatives: comparison of perioperative mortality and long-term survival for cancer surgery. J Clin Oncol 2008;26(28):4626-33.

9. Cheung MC, Hamilton K, Sherman R, et al. Impact of teaching facility status and high-volume centers on outcomes for lung cancer resection: an examination of 13,469 surgical patients. Annals of surgical oncology 2009;16(1):3-13.

10. Chaudhry R, Goel V, Sawka C. Breast cancer survival by teaching status of the initial treating hospital. Cmaj 2001;164(2):183-8.

11. Effects of chemotherapy and hormonal therapy for early breast cancer on recurrence and 15year survival: an overview of the randomised trials. Lancet 2005;365(9472):1687-717.

12. Giordano SH, Duan Z, Kuo YF, Hortobagyi GN, Goodwin JS. Use and outcomes of adjuvant chemotherapy in older women with breast cancer. J Clin Oncol 2006;24(18):2750-6.

13. Visser O, Siesling S, van Dijck J. Incidence of cancer in the Netherlands 1999/2000. Utrecht: Vereniging van Integrale Kankercentra; 2003.

14. UICC. TNM Classification of Malignant Tumours. 6th ed. New York: Wiley-Liss; 2002.

15. Schouten LJ, Hoppener P, van den Brandt PA, Knottnerus JA, Jager JJ. Completeness of cancer registration in Limburg, The Netherlands. Int J Epidemiol 1993;22(3):369-76.

16. www.prismant.nl. accessed on 27-08-2009.

17. Arriagada R, Le MG, Guinebretiere JM, Dunant A, Rochard F, Tursz T. Late local recurrences in a randomised trial comparing conservative treatment with total mastectomy in early breast cancer patients. Ann Oncol 2003;14(11):1617-22.

18. Voogd AC, Nielsen M, Peterse JL, et al. Differences in risk factors for local and distant recurrence after breast-conserving therapy or mastectomy for stage I and II breast cancer: pooled results of two large European randomized trials. J Clin Oncol 2001;19(6):1688-97.

19. Collins ED, Moore CP, Clay KF, et al. Can women with early-stage breast cancer make an informed decision for mastectomy? J Clin Oncol 2009;27(4):519-25.

20. Katipamula R, Degnim AC, Hoskin T, et al. Trends in mastectomy rates at the Mayo Clinic Rochester: effect of surgical year and preoperative magnetic resonance imaging. J Clin Oncol 2009;27(25):4082-8.

21. McGuire KP, Santillan AA, Kaur P, et al. Are mastectomies on the rise? A 13-year trend analysis of the selection of mastectomy versus breast conservation therapy in 5865 patients. Annals of surgical oncology 2009;16(10):2682-90.

22. Ververs JM, Roumen RM, Vingerhoets AJ, et al. Risk, severity and predictors of physical and psychological morbidity after axillary lymph node dissection for breast cancer. Eur J Cancer $2001 ; 37(8): 991-9$.

23. Voogd AC, Ververs JM, Vingerhoets AJ, Roumen RM, Coebergh JW, Crommelin MA. Lymphoedema and reduced shoulder function as indicators of quality of life after axillary lymph node dissection for invasive breast cancer. Br J Surg 2003;90(1):76-81.

24. Roumen RM, Valkenburg JG, Geuskens LM. Lymphoscintigraphy and feasibility of sentinel node biopsy in 83 patients with primary breast cancer. Eur J Surg Oncol 1997;23(6):495-502.

25. Ho VK, van der Heiden-van der Loo M, Rutgers EJ, et al. Implementation of sentinel node biopsy in breast cancer patients in the Netherlands. Eur J Cancer 2008;44(5):683-91.

26. Veronesi U, Paganelli G, Galimberti V, et al. Sentinel-node biopsy to avoid axillary dissection in breast cancer with clinically negative lymph-nodes. Lancet 1997;349(9069):1864-7. 
27. Cox CE, Bass SS, McCann CR, et al. Lymphatic mapping and sentinel lymph node biopsy in patients with breast cancer. Annual review of medicine 2000;51:525-42.

28. Schijven MP, Vingerhoets AJ, Rutten HJ, et al. Comparison of morbidity between axillary lymph node dissection and sentinel node biopsy. Eur J Surg Oncol 2003;29(4):341-50.

29. Aebi S, Pagani O. Treatment of premenopausal women with early breast cancer: old challenges and new opportunities. Drugs 2007;67(10):1393-401.

30. Harlan LC, Clegg LX, Abrams J, Stevens JL, Ballard-Barbash R. Community-based use of chemotherapy and hormonal therapy for early-stage breast cancer: 1987-2000. J Clin Oncol 2006;24(6):872-7.

31. Sukel MP, van de Poll-Franse LV, Nieuwenhuijzen GA, et al. Substantial increase in the use of adjuvant systemic treatment for early stage breast cancer reflects changes in guidelines in the period 1990-2006 in the southeastern Netherlands. Eur J Cancer 2008;44:1846-54.

32. Du X, Goodwin JS. Patterns of use of chemotherapy for breast cancer in older women: findings from Medicare claims data. J Clin Oncol 2001;19(5):1455-61.

33. Laine C, Sox HC. Does practice really make perfect? Annals of internal medicine 2003;139(8):696-8.

34. Louwman WJ, Janssen-Heijnen ML, Houterman S, Voogd AC, van der Sangen MJ, Nieuwenhuijzen GA, Coebergh JW. Less extensive treatment and inferior prognosis for breast cancer patient with comorbidity: a population-based study. Eur J Cancer. 2005;41(5):779-85. 


\section{Captions}

Figure 1: Treatment of breast cancer by stage, the Netherlands 2003-2006

BCS: breast conserving surgery; RT: Radiotherapy

Figure 2: Variation in lymph node dissection in patients with NO breast cancer per hospital by type and average number of NO breast cancer patients per year, the Netherlands 2003-2006

Figure 3: Variation in application of adjuvant systemic treatment to T1T2 NO breast cancer per hospital by type and average number of T1T2 NO breast cancer patients per year, the Netherlands 2003-2006 
Table 1: Number of new cases of breast cancer in the Netherlands, 2003-2006

\begin{tabular}{|c|c|c|}
\hline & $\mathrm{N}$ & $\%$ \\
\hline Total & 51354 & 100 \\
\hline \multicolumn{3}{|l|}{ Year of diagnosis } \\
\hline 2003 & 12460 & 24 \\
\hline 2004 & 12786 & 25 \\
\hline 2005 & 12828 & 25 \\
\hline 2006 & 13280 & 26 \\
\hline \multicolumn{3}{|l|}{ Age (yrs) } \\
\hline$<40$ & 3421 & 7 \\
\hline $40-69$ & 33068 & 64 \\
\hline$\geq 70$ & 14865 & 29 \\
\hline \multicolumn{3}{|l|}{ Stage\# } \\
\hline I & 20404 & 40 \\
\hline$\| A$ & 14525 & 28 \\
\hline$\| B$ & 6163 & 12 \\
\hline IIIA & 3993 & 8 \\
\hline IIIB & 135 & 2 \\
\hline IIIC & 2082 & 4 \\
\hline IV & 2524 & 5 \\
\hline Unknown & 528 & 1 \\
\hline \multicolumn{3}{|l|}{ Morphology } \\
\hline ductal & 40813 & 80 \\
\hline lobular & 5998 & 12 \\
\hline ductal and lobular & 1857 & 4 \\
\hline mucineus & 854 & 2 \\
\hline medullair & 408 & 1 \\
\hline tubular & 576 & 1 \\
\hline other & 848 & 2 \\
\hline \multicolumn{3}{|l|}{ Differentiation } \\
\hline good & 9319 & 18 \\
\hline moderate & 19448 & 38 \\
\hline well/undifferentiated & 14592 & 28 \\
\hline unknown & 7998 & 16 \\
\hline \multicolumn{3}{|l|}{ Hospital type* } \\
\hline small $(<150)$, general & 16699 & 33 \\
\hline large $(\geq 150)$, general & 4636 & 9 \\
\hline small $(<150)$, teaching & 5003 & 10 \\
\hline large ( $\geq 150)$, teaching & 20919 & 41 \\
\hline small (<150), academic & 2469 & 5 \\
\hline large $(\geq 150)$, academic & 1617 & 3 \\
\hline \multicolumn{3}{|c|}{ Teaching hospital internal medicine* } \\
\hline no & 16506 & 32 \\
\hline yes & 30751 & 60 \\
\hline academic centre & 4086 & 8 \\
\hline \multicolumn{3}{|l|}{ Radiotherapy in hospital* } \\
\hline no & 41382 & 81 \\
\hline yes & 9972 & 19 \\
\hline \multicolumn{3}{|c|}{ Region of Comprehensive Cancer Center } \\
\hline 1 & 7004 & 14 \\
\hline
\end{tabular}




\begin{tabular}{lrr}
2 & 4396 & 9 \\
3 & 3882 & 8 \\
4 & 9447 & 18 \\
5 & 5135 & 10 \\
6 & 7404 & 14 \\
7 & 7293 & 14 \\
8 & 2935 & 6 \\
9 & 3841 & 8 \\
Lymph node dissection & & \\
none & 6400 & 13 \\
SNP without ALND & 23064 & 45 \\
SNP with ALND & 6719 & 13 \\
ALND & 15171 & 30 \\
\hline
\end{tabular}

BCS: breast conserving surgery; SNP: sentinel node procedure; ALND: axillary lymph node dissection

* based on hospital of first diagnosis

Table 2a: The unadjusted odds of breast conserving surgery in patients with $\mathrm{T} 1 \mathrm{~T} 2$ breast cancer, the Netherlands, 2003-2006

\begin{tabular}{lllllll}
\hline & $<40$ yrs & \multicolumn{3}{c}{$40-69$ yrs } & \multicolumn{3}{c}{$\geq 70$ yrs } \\
\hline & OR & $95 \% \mathrm{Cl}$ & OR & $95 \% \mathrm{Cl}$ & OR & $95 \% \mathrm{Cl}$ \\
\hline Hospital type & & & & & & \\
small $(<150)$, general & $1.21^{*}$ & $1.01-1.44$ & $0.90^{*}$ & $0.85-0.95$ & $0.73^{*}$ & $0.67-0.80$ \\
large ( $\geq 150)$, general & $1.54^{*}$ & $1.18-2.02$ & $1.12^{*}$ & $1.02-1.22$ & 0.89 & $0.78-1.03$ \\
small $(<150)$, teaching & 1.07 & $0.82-1.39$ & $0.76^{*}$ & $0.70-0.83$ & $0.58^{*}$ & $0.50-0.66$ \\
large $(\geq 150)$, teaching & 1.0 & & 1.0 & & 1.0 & \\
small $(<150)$ academic & 0.95 & $0.70-1.29$ & $0.80^{*}$ & $0.71-0.90$ & 0.88 & $0.71-1.09$ \\
large $(\geq 150)$, academic & 0.98 & $0.64-1.49$ & 0.90 & $0.78-1.03$ & 1.25 & $0.98-1.60$ \\
\hline
\end{tabular}

$* p<0.05$

Table 2b: The odds of receiving breast conserving surgery in patients with $\mathrm{T} 1 \mathrm{~T} 2$ breast cancer, the Netherlands, 2003-2006

\begin{tabular}{|c|c|c|c|c|c|c|}
\hline & \multicolumn{2}{|c|}{$<40$ yrs $(n=2,958)$} & \multicolumn{2}{|c|}{$40-69$ yrs $(n=29,658)$} & \multicolumn{2}{|c|}{$\geq 70$ yrs $(n=10,645)$} \\
\hline & OR a & $95 \% \mathrm{Cl}$ & OR a & $95 \% \mathrm{Cl}$ & OR a & $95 \% \mathrm{Cl}$ \\
\hline \multicolumn{7}{|l|}{ Hospital type } \\
\hline small $(<150)$, general & $1.29 *$ & $1.05-1.59$ & 1.03 & $0.96-1.10$ & 1.00 & $0.90-1.12$ \\
\hline large $(\geq 150)$, general & $1.44^{*}$ & $1.07-1.92$ & 1.02 & $0.93-1.13$ & 0.94 & $0.81-1.10$ \\
\hline small (<150), teaching & 1.14 & $0.84-1.53$ & 0.86 & $0.78-0.95$ & $0.83^{*}$ & $0.71-0.97$ \\
\hline large $(\geq 150)$, teaching & 1.0 & & 1.0 & & 1.0 & \\
\hline small $(<150)$ academic & 0.92 & $0.65-1.29$ & $0.74^{*}$ & $0.65-0.84$ & 0.80 & $0.63-1.01$ \\
\hline large ( $\geq 150)$, academic & 0.90 & $0.55-1.49$ & $0.79 *$ & $0.68-0.93$ & 1.04 & $0.78-1.39$ \\
\hline \multicolumn{7}{|l|}{ Radiotherapy in hospital } \\
\hline yes & 1.19 & $0.91-1.56$ & $1.20 *$ & $1.10-1.32$ & 1.57 & $1.35-1.82$ \\
\hline no & 1.0 & & 1.0 & & 1.0 & \\
\hline \multicolumn{7}{|l|}{ Region } \\
\hline 1 & 0.88 & $0.66-1.16$ & $0.90 *$ & $0.82-0.99$ & 0.97 & $0.84-1.12$ \\
\hline 2 & 0.76 & $0.56-1.04$ & $0.84^{*}$ & $0.76-0.93$ & $1.20^{*}$ & $1.02-1.41$ \\
\hline 3 & $1.39 *$ & $1.01-1.91$ & $1.45^{*}$ & $1.30-1.63$ & $1.24^{*}$ & 1.04-1.47 \\
\hline 4 & 1.0 & & 1.0 & & 1.0 & \\
\hline 5 & $0.70^{*}$ & $0.52-0.95$ & 1.00 & $0.90-1.11$ & $0.75^{*}$ & $0.64-0.88$ \\
\hline 6 & 0.96 & $0.73-1.26$ & $0.73^{*}$ & $0.67-0.79$ & $0.65^{*}$ & $0.56-0.75$ \\
\hline
\end{tabular}




\begin{tabular}{lllllll}
7 & $1.49^{*}$ & $1.13-1.97$ & $1.27^{*}$ & $1.15-1.39$ & $1.85^{*}$ & $1.59-2.15$ \\
8 & 0.86 & $0.59-1.28$ & $0.88^{*}$ & $0.78-1.00$ & 0.98 & $0.81-1.18$ \\
9 & 0.78 & $0.57-1.08$ & $0.65^{*}$ & $0.59-0.72$ & 1.18 & $0.99-1.41$ \\
Incidence year & & & & & & \\
2003 & 1.0 & & 1.0 & & 1.0 & \\
2004 & 0.89 & $0.73-1.09$ & 0.96 & $0.90-1.03$ & 1.01 & $0.90-1.13$ \\
2005 & $1.32^{*}$ & $1.07-1.63$ & $1.14^{*}$ & $1.06-1.22$ & $1.14^{*}$ & $1.02-1.27$ \\
2006 & 1.14 & $0.92-1.41$ & $1.14^{*}$ & $1.07-1.22$ & $1.28^{*}$ & $1.14-1.43$ \\
\hline$*$
\end{tabular}

a Adjusted for radiotherapy in hospital, region, and incidence year

Table 3: The odds of undergoing lymph node dissection by patients with PT1T2 NO breast cancer, the Netherlands 2003-2006

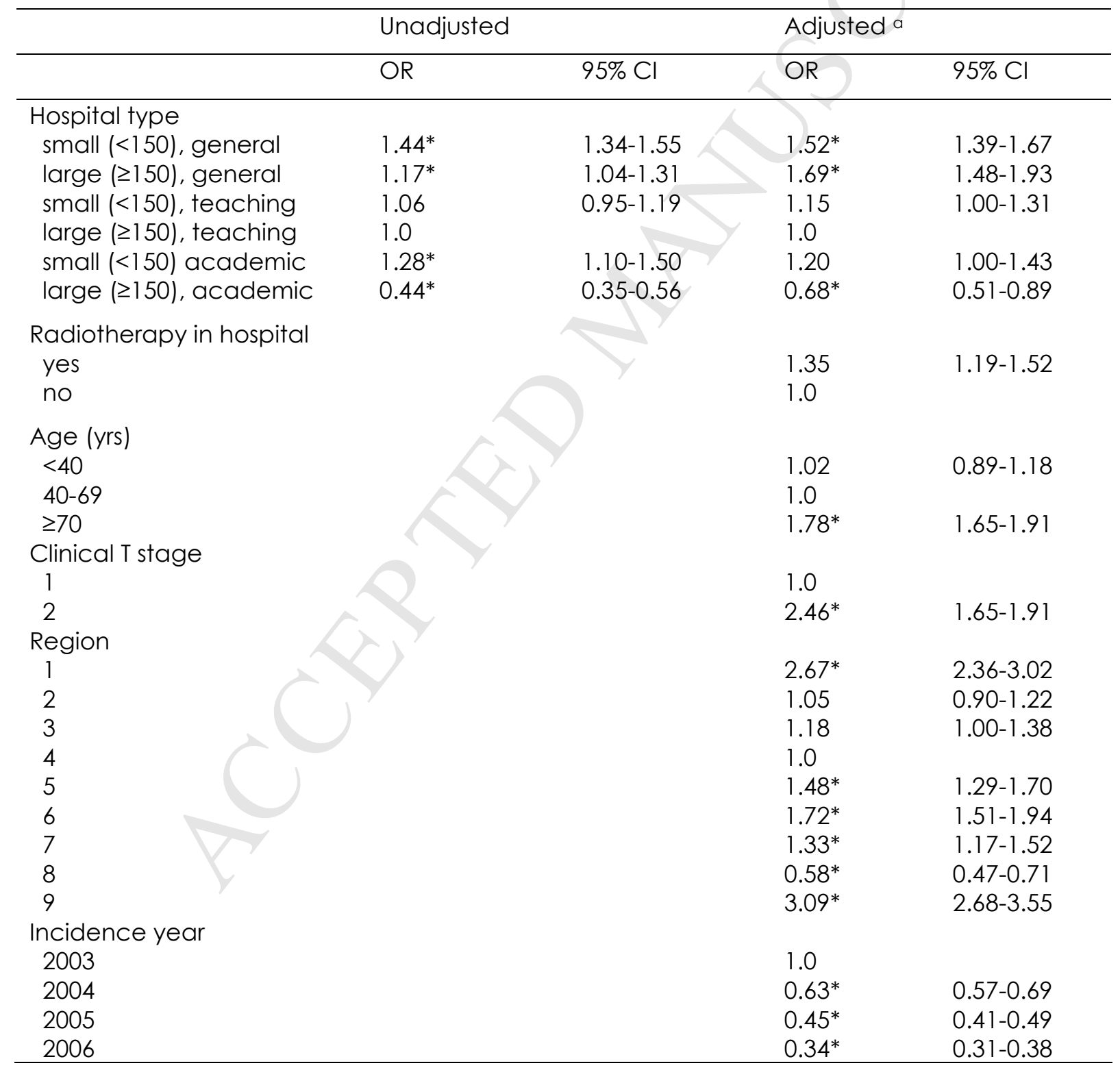

a Adjusted for radiotherapy in hospital, age, clinical T stage, region, and incidence year 
$* p<0.05$

Table 4: The odds of receiving adjuvant systemic therapy by $11 \mathrm{~T} 2$ NO breast cancer patients in the Netherlands, 2003-2006

\begin{tabular}{|c|c|c|}
\hline & OR a & $95 \% \mathrm{Cl}$ \\
\hline \multicolumn{3}{|l|}{ Type of hospital } \\
\hline general & 0.90 & $0.89-1.09$ \\
\hline teaching (internal medicine) & 1.0 & \\
\hline academic & 1.02 & $0.86-1.21$ \\
\hline \multicolumn{3}{|l|}{ Radiotherapy in hospital } \\
\hline yes & 1.0 & \\
\hline no & 0.90 & $0.79-1.01$ \\
\hline \multicolumn{3}{|l|}{ Hospital size } \\
\hline$<150$ & 0.90 & $0.89-1.10$ \\
\hline$\geq 150$ & 1.0 & \\
\hline \multicolumn{3}{|l|}{ Region } \\
\hline 1 & $0.86^{*}$ & $0.75-1.00$ \\
\hline 2 & 1.02 & $0.88-1.19$ \\
\hline 3 & 1.07 & $0.91-1.26$ \\
\hline 4 & $1.34^{*}$ & $1.18-1.52$ \\
\hline 5 & 0.93 & $0.80-1.80$ \\
\hline 6 & 0.88 & $0.76-1.01$ \\
\hline 7 & 1.0 & \\
\hline 8 & 1.00 & $0.85-1.19$ \\
\hline 9 & 1.08 & $0.92-1.25$ \\
\hline \multicolumn{3}{|l|}{ Incidence year } \\
\hline 2003 & 1.0 & \\
\hline 2004 & 1.02 & $0.92-1.13$ \\
\hline 2005 & $1.45^{*}$ & $1.32-1.60$ \\
\hline 2006 & $1.48^{*}$ & $1.34-1.63$ \\
\hline \multicolumn{3}{|l|}{ Age (yrs) } \\
\hline$<40$ & $4.10^{*}$ & $3.54-4.75$ \\
\hline $40-69$ & 1.0 & \\
\hline$\geq 70$ & $0.49 *$ & $0.46-0.54$ \\
\hline \multirow{2}{*}{\multicolumn{3}{|c|}{ T stage b }} \\
\hline & & \\
\hline 2 & $8.11^{*}$ & $7.51-8.75$ \\
\hline \multicolumn{3}{|l|}{ Grade } \\
\hline good & $0.29 *$ & $0.26-0.33$ \\
\hline moderate & 1.0 & $817-958$ \\
\hline $\begin{array}{l}\text { poor } \\
\text { unknown }\end{array}$ & $\begin{array}{l}8.84^{*} \\
1.44^{*}\end{array}$ & $\begin{array}{l}8.17-9.58 \\
1.27-1.63\end{array}$ \\
\hline $\begin{array}{l}\text { a Adjusted for radiotherapy in } \\
\text { grade }\end{array}$ & ospital & idence y \\
\hline
\end{tabular}




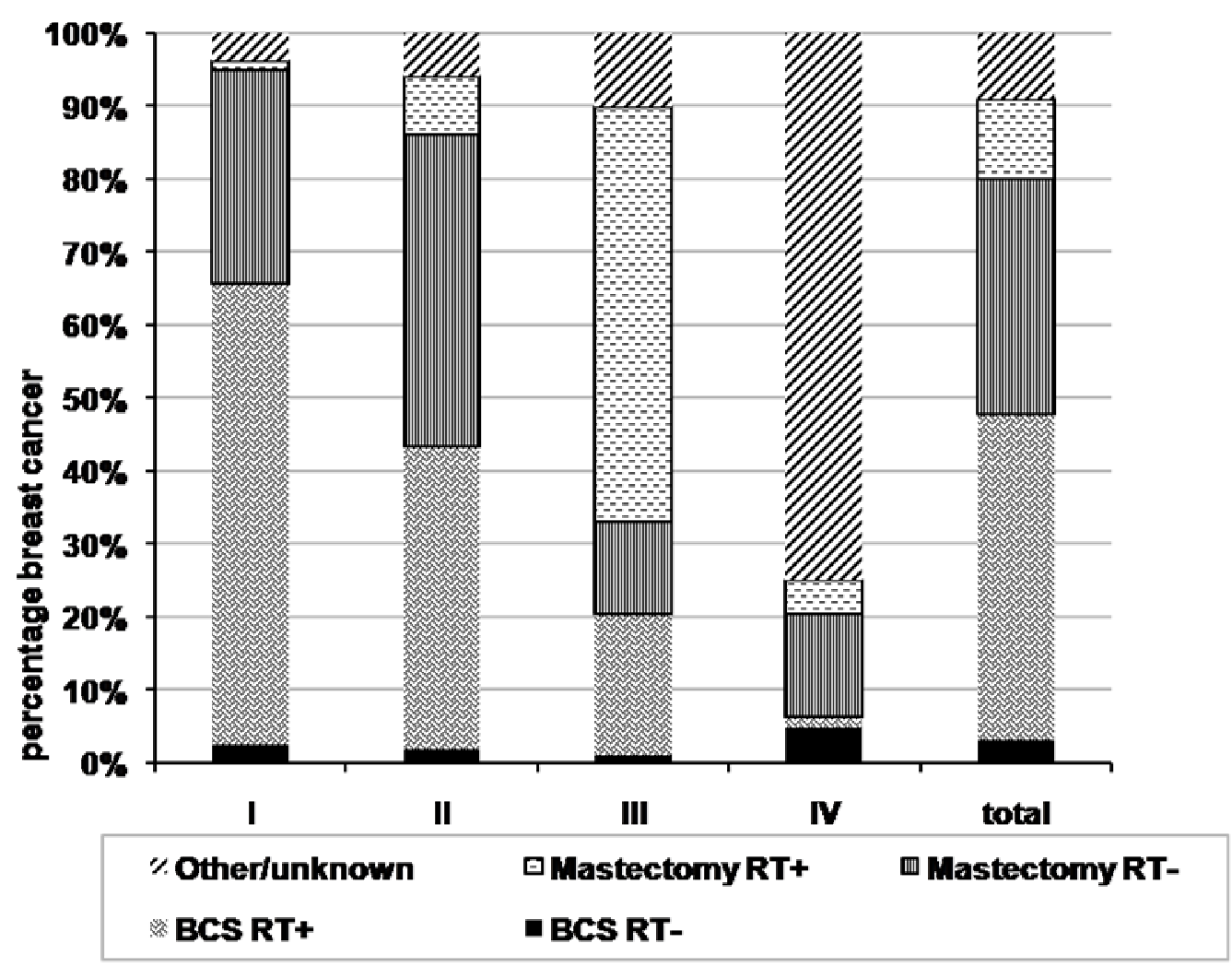




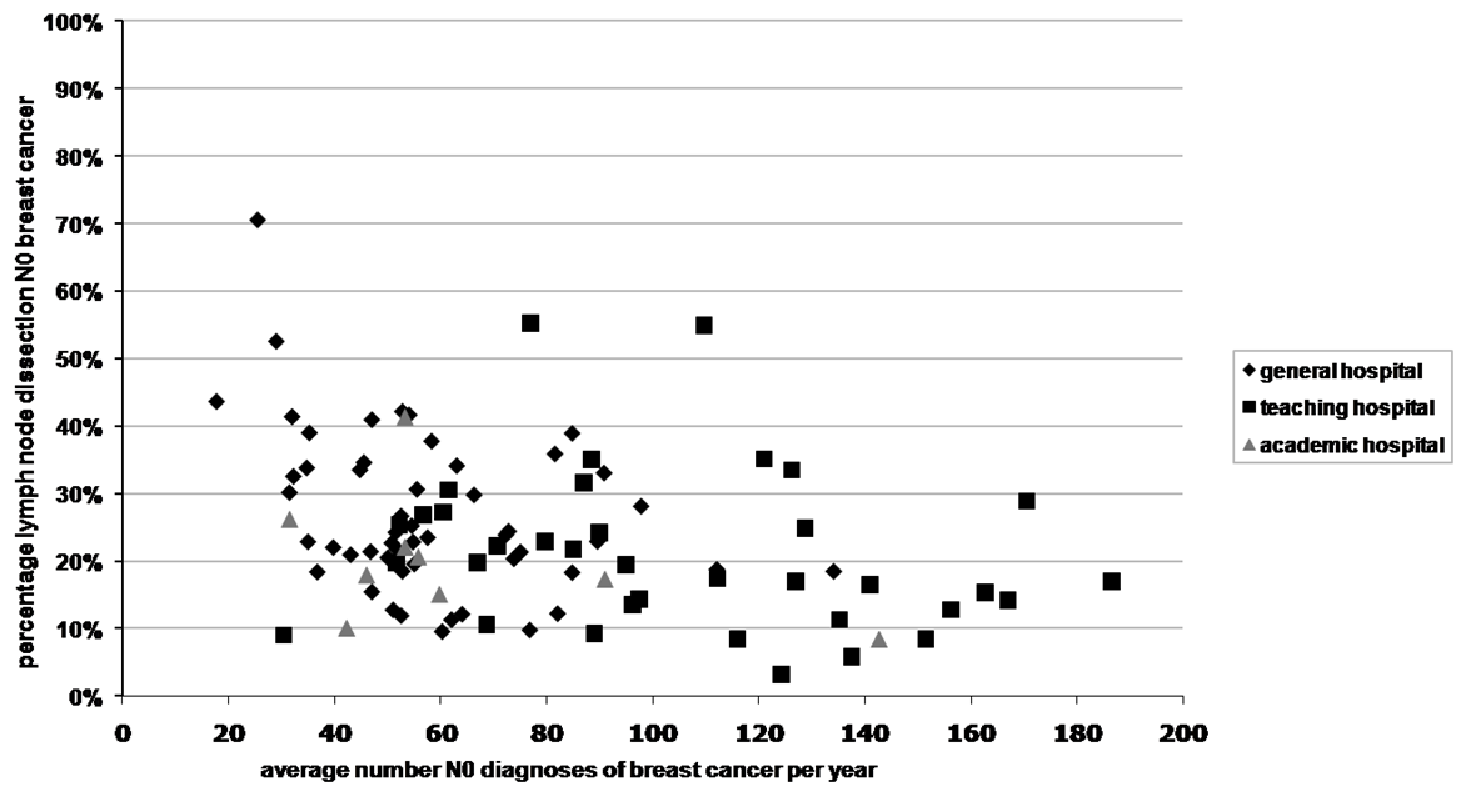




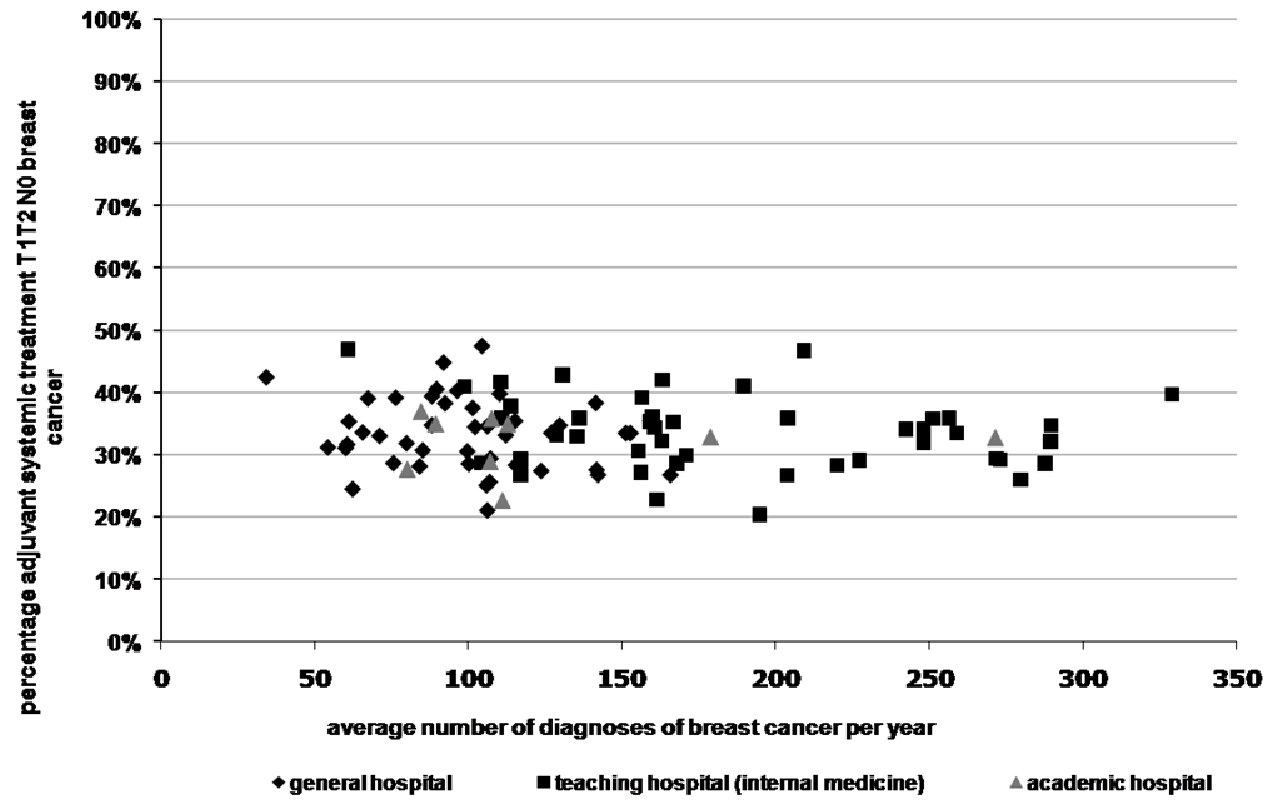

